\title{
Nursing education during a pandemic: Perspectives of students and faculty
}

\author{
Cheryle Levitt, Marguerite Goulet, Jamie Murphy, Rebecca Norman-Eck, Ami Bhatt \\ School of Nursing, State University of New York, Delhi College of Technology, Delhi, New York, USA
}

Received: November 15, 2020

Accepted: November 26, 2020 Online Published: December 15, 2020

DOI: $10.5430 /$ jnep.v11n $4 \mathrm{p} 19$

URL: https://doi.org/10.5430/jnep.v11n4p19

\begin{abstract}
Purpose: Nurses working on the frontlines of the COVID-19 pandemic have experienced a combination of physical, psychological, logistical, professional, and personal challenges. Those nurses enrolled in baccalaureate and graduate nursing degree programs were affected significantly in their ability to remain focused on meeting course expectations while contending with pandemicinduced challenges. Nursing faculty in a public state-based university school of nursing in upstate New York responded by developing initiatives to support students and foster their success.

Results: Supported by unsolicited anecdotal reports, this article describes the experiences and perspectives of nurses in clinical roles working in a pandemic epicenter, while simultaneously completing nursing degree programs. Students were confronted by professional and personal stressors that challenged their ability to manage multiple responsibilities. Faculty supported students with intensive caring and communication, and by selective strategic policy and pedagogical adaptations, while adhering to and preserving program integrity and standards. These four distinct efforts supported student retention and success, and created opportunities for faculty dialogue, assessment, and reflection upon the nature of the changes and plans for future implementation. Self-care was identified as an important coping strategy for both students and faculty.

Conclusions: Faculty believe the four-pronged approach enabled students to succeed in their programs of study and feel supported as individuals and professionals. Despite the continuing global health crisis, there have been numerous positive outcomes and lessons learned by both students and faculty while learning and teaching during the pandemic, with implications for future curricular and pedagogical approaches.
\end{abstract}

Key Words: COVID-19, Coronavirus, Pandemic, Nursing education, Nursing students, Learning stress

\section{INTRODUCTION}

The COVID-19 pandemic has created numerous challenges for nurses and other healthcare workers, particularly those on the frontlines working in epicenters overrun with critically ill patients. The burden and resultant stress on healthcare workers during this time has been multifactorial and well documented. ${ }^{[1-3]}$ In addition to their clinical positions, many working nurses are students in degree programs with added responsibilities and burdens, including time management issues and the ability to focus on schoolwork during the heightened clinical demands of the pandemic. ${ }^{[4,5]}$ While numerous reports have described the difficult conditions for nurses working in COVID-19 clinical environments, ${ }^{[6-8]}$ and the need for adaptations in nursing curricular content to prepare students for present and future pandemics, ${ }^{[1,9,10]}$ few accounts have detailed the logistic, academic, and emotional experiences for students and faculty in nursing education during this unprecedented time. This article is a descriptive

*Correspondence: Cheryle Levitt; Email: levittcg@delhi.edu; Address: School of Nursing, State University of New York, Delhi College of Technology, 454 Delhi Drive, Delhi, New York, USA.

Published by Sciedu Press 
summary, supported by unsolicited anecdotal reports from student emails to faculty, detailing how students persevered and balanced their roles as professional nurses in clinical environments and as nursing students during the period of March-July, 2020.

Teaching nursing students during the COVID-19 pandemic has presented unique challenges for students and faculty members in the United States, the country with the most confirmed cases in the world. ${ }^{[11]}$ The unpredictability of the pandemic that caused overwhelming burdens on the health system in New York (NY) exacerbated the already busy schedules of working nursing students. This was particularly evident for many students in our online RN-BSN and MSN nursing programs in a public state-based university who were employed in the pandemic epicenter of NY state during spring and summer, 2020. While online nursing education provides flexibility for working nurses, the added burden of the pandemic work requirements resulted in physical and emotional exhaustion challenging the structure and expectations of online learning, and retention of students in their programs of study. Faculty provided continual supportive and intensive caring approaches in our nursing education programs to accommodate students while adhering to and preserving the programs' rigor, expectations, and outcomes. The lessons learned by faculty about educating students during a pandemic refined our roles as faculty and impacted pedagogical approaches that will likely extend well beyond the current health crisis.

\section{STUdENTS' PANDEMIC EXPERIENCES}

In NY state, on March 31, 2020, over 75,800 positive cases and more than 1,550 deaths were confirmed, with numbers rising daily at an alarming rate. ${ }^{[12]}$ At the time of the submission of this article, NY has had over 533,587 confirmed cases and more than 33,307 confirmed deaths, ${ }^{[12]}$ and these numbers continue to rise.

Reports from experiences at the beginning of the pandemic from countries with early surges of COVID-19 described the high infection rate for healthcare workers and the need to protect them from exposure and infection from COVID-19 patients. ${ }^{[13]}$ Areas of critical importance identified during the initial pandemic crisis period were nursing shortages, increased work hours, unusual grogginess or tiredness of workers at the end of shifts, insomnia, lack of appetite, disturbed sleep, bouts of crying and anxiety, and psychological stress with the resultant mental health issues of anxiety and depression. ${ }^{[6,14]}$ The descriptions of physical and psychological exhaustion amidst relentless dedication to caring for those who were succumbing to the disease were alarming. ${ }^{[15]}$ These early experiences were predictive of the issues that nurses in the United States and globally would soon encounter in other epicenter areas with rapidly rising COVID-19 cases.

\subsection{Professional stressors}

The multitude and degree of stressors experienced by clinical nurses and other healthcare workers serving in pandemic centers was overwhelming. Compounded by a lack of preparedness for a pandemic, healthcare facilities faced significant surges of critical care patients complicated by an inadequate infrastructure including too few ICU beds, ventilators, personal protective equipment (PPE), and in some cases, capacity for the rising numbers of the deceased. ${ }^{[1]}$ Issues encountered by our nursing students included employment staffing shortages, reassignments to unfamiliar units, mandatory overtime, fear and anxiety over exposure, becoming infected by COVID-19, and the risk of transmitting the virus to family members (see Table 1). Anxiety increased from economic uncertainty ${ }^{[16]}$ due to temporary or permanent furloughs of nurses in units that were not COVID-focused.

Student: I work in a doctor's office and they just told me that I cannot come back to work because I work part-time at the hospital. They are concerned that I will contract COVID and transmit it to them or their patients. I don't know what I am going to do. I am a single mother and work both jobs to pay the bills. I've never seen anything like this. I am stressed beyond words right now.

According to a Medscape poll (May 7, 2020) of nurses and physicians, approximately $75 \%$ of RN and APRNs indicated their work had been altered significantly as a consequence of the pandemic. ${ }^{[17]}$ The upsurge of the use of telehealth required quick adaptation, while others experienced rapid cross-training for different clinical environments while working with unfamiliar or limited resources. Due to the increased complexity of care most cross-training required moving from lesser to greater acuity areas; this affected staff's job security in a variety of ways. ${ }^{[18]}$

Student: They notified us the other night that they are keeping 11 nurses for the ICU team to use, but the rest of us must take our personal time or be furloughed. Just a mind blowing notification after we were all run ragged on one of the highest demand floors in the hospital. They have closed half of our floors in the facility and are converting everything else to ICU beds. It is so sad, we had to say goodbye to nurses of 30 years at the facility and long-term travel nurses who were a part of our floor.

In some cases, as the pandemic progressed, some nurses who had been furloughed reported being reassigned for family grievance support or to fill staffing gaps by nurses who were unable to work due to falling ill from COVID-19. 
Table 1. Challenges for students working as registered nurses during the pandemic

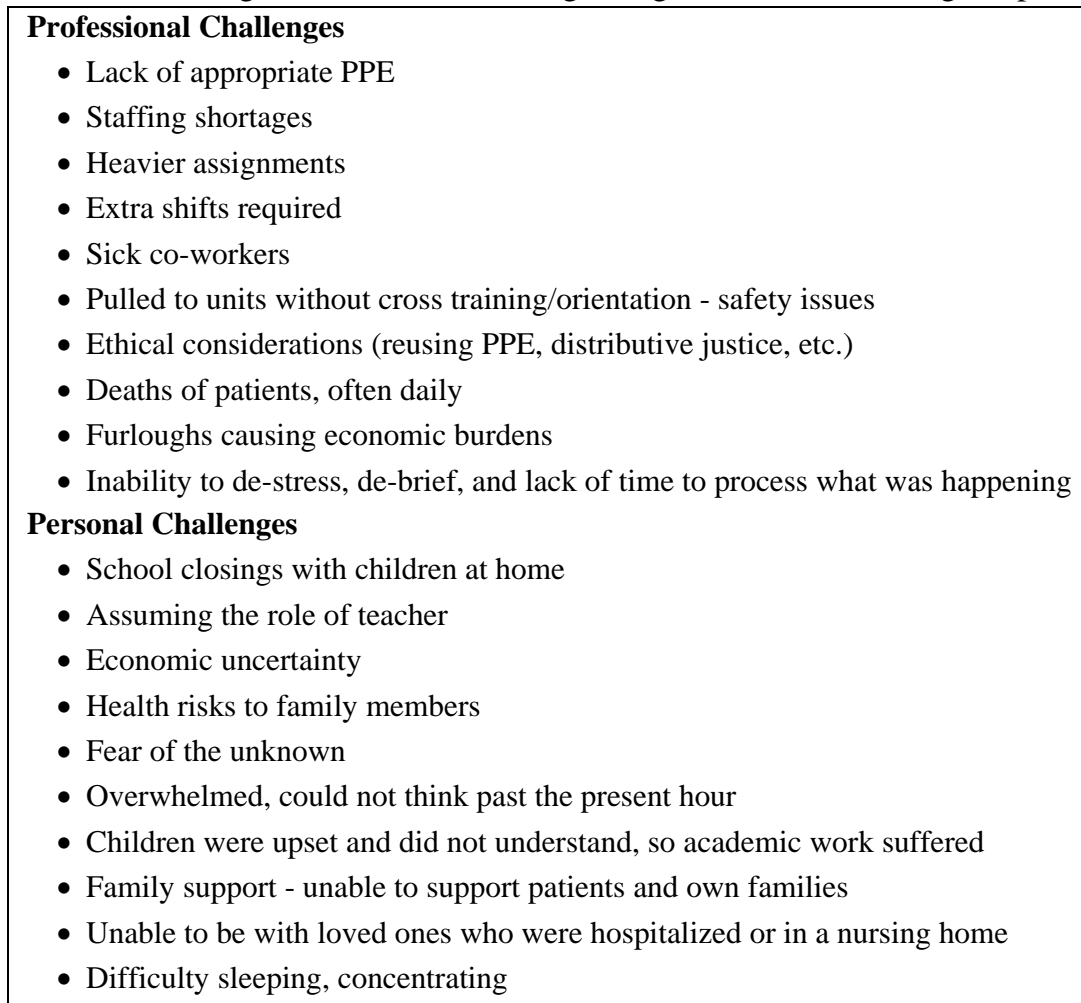

Student: We've had many employees test positive that I have worked closely with without PPE due to the shortage. I have also been forced into a rapid ICU crash course training to prepare for the influx of COVID patients in the ICU. It has been my normal full-time work week plus the extra training. I am beyond spent mentally at this time. I have to wear a surgical mask at home continuously due to the exposures and my fear for my family.

Student: Tension has been high in the hospital since the covid pandemic has started. A lot of people are stressed, scared, and overwhelmed. Therefore, we have all experienced frustrating miscommunication between each other. There are a lot of changes happening daily, and supplies are running low which makes the situation even more frustrating.

Nurses reported functioning in the role of surrogate family members for dying patients due to visitor restrictions, navigating increased ICU admissions, bed shortages, rapidly evolving institutional policies such as shared ventilators, fluctuating standards of care, and the uncertainty of new clinical protocols. Caring for high numbers of patient deaths without family members present, informing family members using electronic communication, and a lack of visitors significantly increased nurses' personal grieving for their patients and family distress. ${ }^{[19]}$ These issues have become more widespread as the pandemic continues to spread; they are a reflection

Published by Sciedu Press of meeting complex medical and psychosocial needs of the pandemic patient population.

Student: Grieving at a distance has been a learning curve and heart wrenching, especially when you are running on empty to begin with. Coming to grips with the fact that right now being a nurse means sacrificing the ability to physically be there to comfort my loved ones in exchange for comforting strangers was a massive hurdle. Not once did I ever think when I went to nursing school that that would happen.

Student: I can say this has given me a new level of understanding and sympathy when it comes to calling the families of patients who have passed with no visitors or goodbyes. Where I once could not find the words, I am able to console and wholeheartedly sympathize in a time when they need it most.

Nurses have experienced some impact in nearly every clinical practice setting. The sudden volatility and unpredictability in the nursing employment role was a new phenomenon in a stable profession and caused increased insecurity and anxiety.

\subsection{Personal stressors}

During this period, many students worried for the safety of their own families ${ }^{[20]}$ and some chose to self-isolate and live in separate facilities, including hotels, garages, or backyard 
tents to avoid possible transmission. Enhanced safety precautions such as changing clothes and disinfecting used items and hands before reentering their homes became routine practice. School and daycare closures necessitated homeschooling their own children or finding arrangements during working hours. Nurses were frightened and exhausted, but remained resilient, agile, and dedicated to their nursing roles. ${ }^{[5,21]}$

Student: I care for a very delicate population. I work as an infusion nurse and administer chemo and other infusions in an oncology clinic. We are trying to keep as safe as possible. I pray that this resolves soon. I am afraid for my patients and their families as well as my own family. My husband has a history of cancer and has lymphoma. The world needs all of our prayers right now!!!

The professional apprehensions and personal challenges created a heightened anxiety and unrelenting pressure and grief in the staff ${ }^{[20,21]}$ that was a constant presence throughout this period.

Student: I am trying so hard to keep my head above water and not miss the lessons these past few weeks have got to offer. There has to be a silver lining. There is no way the world is meant to be this cruel.

The communications by our students expressed both their professional and personal challenges. The added obligations of school responsibilities were often perceived as burdensome and unachievable, even as many students were approaching program completion.

Student: This past 2 weeks I have worked 6 different units and in roles I have never been fully prepared for, with resources at a minimum. One unit didn't have an EKG machine when I called a rapid. Another night I was thrown into resourcing for the ICU where the critical care nurse I was with had 4 patients, though I can hold my own as a nurse I have less than a year of experience and zero in critical care.

\section{LEARNING UNDER STRESS}

Nursing students are recognized as having an underlying level of stress that often ranges from moderate to high, as students face the reality of the role. ${ }^{[16,22]}$ Common stressors reported among nursing students include managing expectations, ${ }^{[23]}$ mastering clinical skills ${ }^{[24]}$ rigorous assignments, heavy workloads, ${ }^{[26]}$ stringent examinations, ${ }^{[26]}$ conflicts with faculty and peers, ${ }^{[2]}$ and the fear of committing errors when providing patient care. ${ }^{[27]}$ Students in nursing programs report feeling overworked and unprepared and have conflicting demands. ${ }^{[25]}$ These feelings are compounded when life or societal events affect or interfere with normal or routine functioning. Higher levels of stress can impair performance, affect memory retrieval, ${ }^{[28]}$ and result in difficulties in concentration. ${ }^{[29]}$ The pandemic-induced challenges resulted in greater stress from multiple sources, and our faculty anticipated the likely impact upon students' learning and performance.

\subsection{Professional challenges affecting learning}

The pandemic required clinical performance expectations well above the usual staff role requirements. Working or studying during an acutely stressful time can affect cognitive functions, including updating memories as new information occurs, difficulties in learning, ${ }^{[28]}$ and the ability to adapt. ${ }^{[30]}$ Romero-Blanco et al. ${ }^{[31]}$ reported on the effects of poor sleep quality in nursing students during the pandemic, with possible reduced performance, dietary changes, and even potential aggressive behaviors. Communications between students and faculty reflected multiple sources of stress, ranging from inability to focus to inability to submit assignments.

Student: Stress could definitely be getting the best of me. I'm having dizziness and episodes of tachycardia and ended up in the emergency room mid shift tonight and will likely be admitted for observation... I sincerely wish this whole year was a bad dream I could just wake up from.

Student: This week I was absolutely exhausted and completely forgot what day it was, missing the response post for the assignment.

The desire of students to remain in their education programs was evident, but they were compromised by events that were spiraling beyond their control.

Student: I wish this was not the first impression of me as a student, this is not my standard. Nothing about any of our lives right now is standard. I have talked to my academic advisor in regards to withdrawing from this course and after deep thought and some reassurance I am deciding to attempt to put my best foot forward and continue on. I understand the value of getting my BSN and the contribution the knowledge I gain through this program can make on the care I provide.

In addition to our students helping others, some needed to stop and recover from COVID-19 themselves. As healthcare workers began contracting the virus, they experienced health issues and tried to remain in school, when possible.

Student: I have not had a chance to post, I'm struggling with this COVID diagnosis. I had high hopes I would be feeling much better than I am, I have had 103 temps for over a week. I do not wish this on anyone. Will try to post in class tomorrow. 


\subsection{Personal challenges affecting learning}

Students needed to express their personal experiences, emotions, and the challenges they were facing outside of school and they communicated this vulnerability frequently with their faculty.

Student: It has been a hell of a week. I volunteered this past week to work in my old ER to help with the influx of COVID19 patients and ended up being one myself. I am currently taking Patho [pathophysiology] as well as this course and will be posting as I can. This is a very trying time for all and I contemplated dropping these classes and re-taking in the fall, but I am now on a 14-day quarantine and would like to try my best to get through this.

Students reported economic burdens due to layoffs including economic burdens due to layoffs including increased food and utility bills, time constraints due to many added hours of childcare, and household responsibilities for added family members at home during times of lockdowns and quarantines. Home responsibilities included providing care for elderly parents, family members falling ill and needing in-home isolation, and worrisome growing gaps in routine healthcare (see Table 1). These issues created massive time management issues and wreaked havoc with their normal schedules for coursework, resulting in increased anxiety levels above their already high level of worry.

Student: I should have been more honest with myself and upfront with you about how overwhelmed and down right exhausted I was in the face of the COVID chaos. It all just happened so fast. I figured if I could throw something together and turn it in on time, I could redeem myself later.

One student shared her concern for a family member in a nursing home whom she was unable to visit. She was anxious about the quality of care without family presence to enable monitoring, and for the emotional well-being of their loved one who was isolated from visitors. In addition, work expectations were increasing while staff was decreasing due to falling ill themselves.

Student: We are to continue to work until we have symptoms. I have 3 kids in a 2-bedroom apartment with all of them being home now and trying to homeschool everyone. I am just a little beyond emotional right now, please understand my inability to focus the way I should on this paper. I am wholeheartedly trying to complete this course in the expected deadlines provided but it is already Wednesday and I don't even have half of the paper done.

Student: Though technology has been one of the biggest blessings of this whole crisis I truly cannot wait to trade phone calls and photo exchanges for hugs and real family time. I never was one to take it for granted to begin with but, I will cherish it that much more.

The uncertainty, fear, and confusion remain a constant for many students, as the fall, 2020 season is experiencing increased positive cases nationally and COVID-19 and critical care units are once again filling with patients. The cycle is repetitive and will likely last through the pandemic period.

\section{TEACHING UNDER STRESS}

Nursing educators have been affected greatly by the pandemic. ${ }^{[5,32,33]}$ The new challenges experienced by our nursing students were novel for even our most experienced faculty, who despite emergency and critical care trauma experience, had little exposure to sustained crisis nursing. As the COVID-19 numbers rose quickly, intervention was needed to support our students to cope during this time. Faculty responded promptly to the perceived needs of the students with plans for a unified approach by consensus. Our faculty met early on to brainstorm and plan how to meet students' needs while preserving the quality, rigor, and professional values and standards that guide our programs (see Table 2). Given the early stages of the pandemic and the lack of literature on nursing education during the pandemic, our faculty used theory, intuition, pedgogical strategies, and our own experiences to guide educational decisions.

\subsection{Clinical practicum placements}

An immediate problem was the complete closure of all clinical sites to nursing students. Dewart et al. ${ }^{[34]}$ reported on the lack of clinical sites due to facilities withdrawing from student placements, and the concerns over nurses being educated with the requirements of social distancing, quarantines, and lack of frontline experiences. Throughout the country, clinical placements were transferred to simulations, case studies, and other methods; assignments were reformulated to accommodate the clinical practice expectations. With the cessation of all student practicum placements alternative assignments that would meet related student learning outcomes were approved by our State Education Department Division for Professional Licensing. These have been approved through this calendar year and are expected to continue until agency placements resume.

Faculty: I found myself assuming the role of student practicum preceptor for 20 students, which increased my workload substantially. There are days when there are just not enough hours to complete all that is required. 
Table 2. Challenges for nursing faculty members during the pandemic

- Quick course modifications while maintaining quality, rigor, and outcomes

- Offering greater flexibility for deadlines, and modified assignment and discussion requirements

- Simplification of directions and rubrics

- Creating alternative practicum experiences as clinical placements were closed to students

- Tracking extensions for students who missed submission deadlines

- Assuming roles of professor, parent, nurse, counselor, social worker

- Helping students with loss, including personal and patients

- Volunteering or working in clinical roles, experiencing similar clinical challenges as the students

- Emotional turmoil including feelings of helplessness, anxiety, depression

- Time management; children at home needed assistance with schooling and supervision

- Modification of schedules and routines to accommodate students' needs

- New experiences, professionally and personally

- Needing extra sensitivity on sharing pandemic news, if not directly related to course

- Putting emotions aside to help our students

\subsection{Course accommodations}

During this uncertain time, a balance is required between the societal obligation to educate healthcare professionals and the current health needs caused by the pandemic. Students required support in order to remain in classes and fulfill their requirements. The first step was to identify the current issues faced by our students, then examine possible approaches and solutions, and adapt the curriculum, pedagogical approaches, and engagement with students.

Siciliano et al. ${ }^{[32]}$ discussed the need to balance ethical principles with allowances made to students during this time, and the need to maintain quality and rigor. Our faculty responded to this challenge collectively and adapted course expectations where possible to lessen the pressure. Examples include reducing the length of scholarly writing assignments, number of slides in presentations, and numbers of questions within a discussion. Savitzky et al. ${ }^{[16]}$ studied students during the third week of a national lockdown in Israel, in Spring 2020. Results showed high levels of anxiety among nursing students and emphasized the crucial role of faculty in providing a stable educational structure, continual communication about changes, and establishing a sense of control by students over their program of study. Efforts in our program were made to help students with time management, the unpredictability of their schedules, and their overall anxiety and stress levels that were being communicated to faculty.

Student: I apologize for my response not being submitted on time. My unit has recently become part of my hospital's covid response team and it has been very overwhelming, with extensive hours. I brought my laptop to work but in this transition, period there simply was not enough time.

Student: It's been tough trying to play catch up, I feel as though I can never get ahead. With this crisis, things in the hospital are busy and it seems as though life has forever changed. Mentally I am not doing so good, but I have to be strong for my family.

\subsection{Student support}

Concern for students' physical and psychological welfare weighed heavily upon faculty as the pandemic escalated. The convenience of our programs already being delivered online enabled avoidance of the often-reported difficult transition from face-to-face to virtual learning. ${ }^{[9,10]}$ Our goal was to foster students' ability to be successful while acknowledging their difficult professional and personal experiences filled with pain, loss, uncertainty, fear of the unknown, and emotional and physical exhaustion. It was imperative that their education continue as planned, thus it was an opportunity to be creative, innovative, and supportive, while demonstrating caring at a higher level. Brunworth ${ }^{[4]}$ reflected on the need to centralize students' wellbeing at the core of every decision while educating nurses during the pandemic and found a strong relationship between faculty support and students' success.

Jean Watson's theory of caring describes the interconnected roles of the caregiver and patient in the promotion of healing. ${ }^{[35]}$ Watson's transpersonal caring theory embraces the core concepts of intentionality, authenticity, and caring consciousness as a basis for compassionate nursing practice. ${ }^{[36]}$ Caring theory provided a foundation for the nurse educatornursing student relationship becoming a key focus in the planning and determination of curricular revisions that supported students' needs. Through the use of intensive caring actions by faculty, students were supported to be resilient, adapt to learning, and succeed in the midst of a highly stressful and anxiety-laden time. Faculty often filled the role of a comforting listener by providing understanding, sympathy, 
and support.

Student: Yesterday was my first day back to work since having COVID, which I caught at my job. I came back to a locked unit and about 43 positive cases out of 51 total ICU patients. It's a total madhouse and absolutely exhausting. I'm really hoping that I can withstand all of this chaos and continue to work on my school work. I appreciate you offering me extra time to complete my assignments and discussion questions.

\subsection{Program adaptations}

Adaptations to policies were made by consensus using discussion and anonymous electronic polling during faculty meetings. Examples included requirements for attendance and participation, specifically in online discussion forums. The expected number of responses was decreased, and the participation requirement was adjusted to increase flexibility. All synchronous meetings were cancelled due to the unpredictability of students' work and home schedules, and asynchronous alternatives were designed using technology tools. While students enjoy the occasional synchronous class meeting during online courses, they expressed gratitude for the flexibility during this time. Assignment deadlines were extended, with flexible turn-in options in many classes where students could decide when to submit their assignments. Penalties for late assignments were often waived or reduced, and the options for Incomplete Grades were broadened to provide extra time for completion. Without these adaptations, many students would have been unable to continue their courses. Faculty maintained an open policy of communication, increased accessibility, flexibility, and an open mind towards change.

Faculty: I kept in frequent contact with students, sending supportive emails, and for many, offering extensions. While some students asked for extensions, I felt it was difficult for other students to ask, and many appreciated the offer, while some did not take me up on these changes.

Throughout this period, faculty were cognizant of the course outcomes and carefully monitored the quality of the work to ensure compliance with student learning outcomes. To faculty's surprise, many students achieved high to outstanding levels of success in their assignments, despite their time and work/life constraints. This led to faculty discussions of whether any of these changes could become permanent. It has prompted a reexamination of whether our original assignments were perhaps heavier than necessary to achieve the learning outcomes.

Many students were able to apply course content to concurrent lived experiences during the pandemic in RN-BSN courses, and this helped them to channel their stress and tension into productive learning outcomes. For example, students in the Health Care Policy course integrated their clinical work into the creation of potential legislative platforms to ensure the provision of adequate PPE and mental health services for healthcare workers. Students in the Epidemiology course understood and appreciated the relevance of the concepts, principles, and learning activities as they were living and working during a pandemic. Course evaluation comments indicated the Epidemiology content was timely and relevant for learning how to shape public health policies and how healthcare professionals detect, monitor, and prevent the spread of illness. Students engaged in disease management by staying informed of the current guidelines in the surveillance, prevention, and treatment of COVID-19. Our students indicated that they are able to apply emerging practices to act as resources for their colleagues and communities on how to prevent disease transmission, as well as recognize evolving signs and symptoms of COVID-19.

\subsection{Faculty fatigue}

Faculty expressed their own fatigue at the end of the semester, especially in classes where students needed flexible due dates and may have exceeded them. The need for self-care for both students and faculty became apparent as the pandemic unfolded. The routines of class management including ongoing communication, discussion posting, and grading were interrupted and less organized, due to the necessary flexibility introduced to help students. Faculty were more lenient, flexible, and open to the unexpected, but this created new questions of the limits and lengths of time to these approaches. Open and frank discussions on how to provide caring and support while adhering to program expectations prompted discussions on ethical, programmatic, and pedagogical decisions during faculty meetings. Decisions were made for how to proceed and on the timing of these changes. The priorities were integrity of teaching and maintaining the professional standards and expectations balanced by the need for student support (see Table 2).

Faculty: The pandemic itself was a challenge but trying to explain alternative assignments in lieu of a practicum also became a challenge. Students were disappointed that they could not engage in the clinical setting to acquire their hours. Another challenge was keeping up with late assignments and following up with students who required additional support or help. I found myself working more hours and I had to take the advice I was giving to students for self-care.

\section{LESSONS LEARNED}

The pandemic crisis has been an example of how students may need support during their journey to successful man- 
agement and completion of their education. Viewing the student in a holistic sense, with personal and professional challenges and as part of the greater society in need, guided the decisions made during this extraordinary time. Upon self-reflection of the faculty, it became clear that a multipronged interventional approach was necessary to address their anxiety and foster success (see Figure 1).

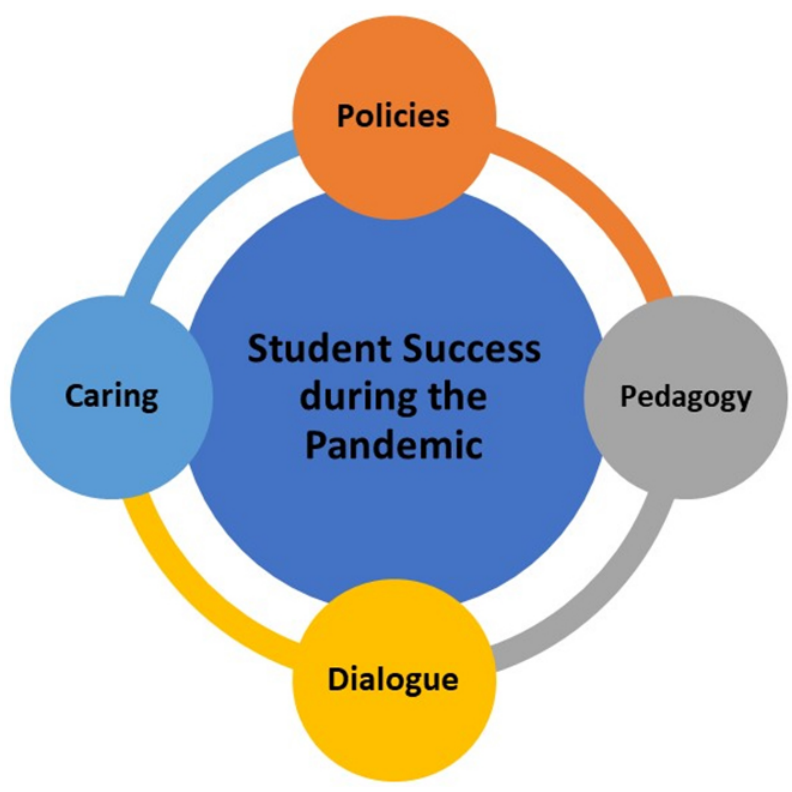

Figure 1. Pandemic teaching strategies for student success

\subsection{Policies}

Deadline flexibility alleviated the stress that the pandemic caused regarding altered work, personal, and childcare arrangements. The flexible policies for Incomplete Grades provided valuable extra time and proved to be a lifeline for some students. This provided a way for those students who contracted COVID-19 and needed recovery time, or those who were unable to complete the required assignments in time to complete their course. Some students needed help with time management and/or varied options for assignment completion.

Teaching through the COVID-19 pandemic necessitated a reevaluation of numerous established nursing program policies and individual course expectations. Adaptations affected due dates, discussion participation, and attendance policy requirements. As a result of the modification to the participation policy, faculty concurred that a permanent change would be implemented, from three days to two days per week. Faculty evaluated every course assignment and selected modifications were made when possible to the requirements in the discussion forums. This was especially helpful to assist students to have extra time for the alternative practicum experiences.

\subsection{Pedagogy}

Several distinct changes affected the programs' pedagogy during this time. The alternative assignments for the precepted practicums were designed, approved, and delivered with ongoing communication in several forums, so students were aware of the new expectations. These had flexible deadlines, and students greatly appreciated the ability to complete their requirements asynchronously.

The inclusion of pandemic content whenever possible into the lessons brought increased relevance to learning that students greatly appreciated. This broadened the knowledge base of the pandemic and current reality, and enabled students to reflect and contribute from their ongoing experiences. It was cathartic for many students to apply their professional experiences to their studies and have supportive peer-to-peer dialogue.

Our program has multiple narrative writing assignments as scholarly papers and in discussions. Several of these were converted into bulleted writing assignments, and students found they were able to provide the same information and saved time from creating scholarly papers. Eliminating synchronous presentations and meetings was well received, despite the loss of peer encouragement and face-to-face sharing. The use of audio platforms that enable dialogue is a popular choice and enabled sharing and communication, albeit asynchronously.

The class discussion forum format was maintained, however with fewer discussion questions within them and lower word counts, when required. The requirement for supporting submissions with evidence and scholarship was retained, consistent with our program expectation of evidence-based practice. Students managed to fulfill these requirements fully, and this has served to provide faculty with fresh perspectives on the delivery of this instructional method.

The various changes in pedagogy helped our students meet the learning and program outcomes, which remained unchanged. The priorities in adapting assignments were to preserve the rigor, integrity, relevance, and quality of our programs, while ensuring assignments were designed to maximize students' time management and learning needs.

\subsection{Dialogue}

It was vital to use every opportunity to communicate promptly with students via the learning management system, email, phone calls, or a virtual meeting platform. Students want and need support, ${ }^{[29]}$ and most were resilient, courageous, and dedicated to their studies in whatever way was feasible. At times, some students expressed an inability to think or concentrate due to the professional or personal 
ramifications of the pandemic. Listening was key to understanding what students were experiencing, and providing support, encouragement, empathy, and positive feedback via emails, online discussions, and messages of praise for excellent academic work were essential and valued by students. Students expressed appreciation for positive and encouraging comments, honesty, and flexibility.

Communication with online students needs to be deliberate, frequent, and meaningful because they do not have the benefit of nonverbal messages of support or the physical presence of the instructor or other students. ${ }^{[37]}$ Transparent, caring, and compassionate communication with students will continue to define effective online teaching and learning practices. The pandemic accentuated the need for even more clear, substantive, and direct communication with students, which has always been a hallmark of our programs.

Faculty communicated more frequently than usual, sharing supportive emails and messages regularly throughout their courses. Some faculty set up chats in their classes dedicated to sharing ongoing experiences, thereby creating a safe place to express the students' new realities. Our attempts to set up a program-wide site for sharing stories was not successful, as students preferred to share in their class chat rooms or with faculty directly. The sense of camaraderie and sharing contributed to a positive atmosphere in the class learning community.

\subsection{Caring}

While our faculty are engaged and communicate frequently with students in normal times, during the pandemic the caring and communication were increased substantially by emails, phone calls, and video chats. Faculty were very concerned about their students' mental health and coping abilities, and the academic advisors provided support continuously, as well. These issues resulted in discussions at faculty meetings to process and reflect upon how best to help our students and help ourselves to understand our responses and range of emotions during this time.

Faculty: I found this past session very sad and discouraging. I felt powerless when learning of the unsafe working conditions, the concerns about returning home every day worried about infecting their family. I imagined my students walking past the refrigerated trailers housing the temporary mortuary.

When a student was diagnosed with COVID-19, we had great concern for their personal health and wellbeing while trying to balance reaching out to the student and allowing adequate time for rest and recovery. Faculty activities included sending caring messages along with academic updates and staying or-

Published by Sciedu Press ganized while students were submitting assignments at times that differed from the original deadlines. Keeping track of late assignments and grading them promptly to furnish feedback was essential to student progression. This all required efficient educator organizational and time management skills.

Student: I can't thank you enough for accommodating us by reducing the number of discussion responses per week. It makes those of us who are working feel appreciated and understood. It will also make things so much more manageable as the course goes on.

Responding to students with compassion, understanding, and empathy validated the students' experiences, fostered transparency, and allowed students to maintain some sense of equilibrium while in a state of chaos. It was apparent that our students had extraordinary needs, and our role and responsibility as faculty was to provide intensive caring for them throughout this period. Just as they provided intensive care to their patients, they needed the care for themselves as students.

Faculty: Most importantly, we learned that through compassion, kindness and understanding, we are able to help each other.

Faculty: As a faculty member here we are always encouraged to be compassionate and understanding with our students. Students were appreciative of the reduction in responses for discussion posts or just having someone to talk to when they felt so isolated. I sent many more emails for support, posted encouraging announcements, and offered video meetings to clarify any questions or just to talk.

Some faculty members were employed as clinicians in New York caring for patients themselves, as contact tracers, and engaged in the roles of parent, teacher, nurse, and professor. This enabled an additional layer of empathy, as faculty understood some of the experiences of our students.

\subsection{Implications for nursing education}

The COVID-19 pandemic enabled a fresh look at our curriculum, and it was found to be productive and enlightening. Students felt the caring and kindness at a time of increased vulnerability. Ingraham et al. ${ }^{[38]}$ found proactive faculty support and caring behaviors builds authentic relationships with students, leading to academic student success. An important outcome of this stressful period was that swift, frequent, and direct communication and individual intensive caring for students was essential and will continue.

Many practicing nurses have chosen their profession from a desire to provide compassionate care for others. However, due to the enormity of the needs before them, nurses found 
themselves struggling to balance patient care responsibilities with self-care needs. Our plan to provide intensive caring to our students to help them manage their studies and remain in school was successful. The attrition rate during this time was very low, and those that did need to defer one semester due to the pandemic have returned. Concerns exist that as the pandemic will wind down, there will be lingering effects, including emotional exhaustion and post-traumatic stress disorder symptoms. ${ }^{[15]}$ It is our hope that caring, support, and the ability to complete their planned education will help to mitigate at least some of the despair experienced by many of our students during the first surge.

Hofmeyer et al. ${ }^{[21]}$ describe the practices of self-awareness and self-compassion and offer tips and resources to foster self-care for nurses. Nursing self-care is in fact paramount for patient care as it allows for the maintenance of resiliency in uncertain times, emotional regulation, and the demonstration of empathy and compassion. Practicing self-care includes taking adequate breaks, ensuring adequate sleep, maintaining good nutrition and exercise patterns, and seeking support from a therapist when needed. ${ }^{[21]}$ Leigh et al. ${ }^{[39]}$ acknowledged the need for redefining nursing education during this time and recommended self-care for students and faculty alike as necessary during this difficult time. Our experiences supported the need for self-care and raised the awareness for consideration of inclusion of this and related topics in the curriculum. As a result, the faculty are reviewing the programs' curricula for content related to coping with stress and adapting to it, resilience, self-care, and how to recognize the need for help and obtain it.

\section{Conclusion}

The pandemic has presented numerous challenges to professional nursing practice and education. These challenges can be viewed as opportunities for broadening caring approaches for students and being open to changes in educational approaches. Our faculty believe the multi-pronged approach of adaptation of policies, pedagogy, increased dialogue, and intensive caring enabled students to retain their student status, succeed in their programs of study, and feel supported as individuals and professionals. Given the uncertainty of the length of the pandemic and the continual anxiety exhibited by our students, these approaches can be applied for the duration and in similar high-stress situations. The added measures of empathy, open mindedness, and flexibility contributed to student resilience. Student feedback indicated that, to a greater extent than prior to the pandemic, they recognized their professors as their advocates and appreciated the opportunity to retain some normalcy during a time of turbulence. Despite the continuing overwhelming global health crisis, there have been numerous positive outcomes and lessons learned for both students and faculty while learning and teaching during the pandemic. Based upon the intensity of students' experiences and the prolonged pandemic there are multiple topics for research including student resilience, coping mechanisms, stress management, and the need for self-care as well as teaching-learning strategies during times of acute or chronic crisis.

\section{CONFLICTS OF INTEREST Disclosure}

The authors declare that there is no conflict of interest.

\section{REFERENCES}

[1] Leigh J, Bolton M, Cain K, et al. Student experiences of nursing on the front line during the COVID-19 pandemic. Br J Nurse [Internet]. 2020 Jul 10; 29(13): 788-9. PMid:32649251 https: //doi.org/10.12968/bjon.2020.29.13.788

[2] Morley G, Grady C, McCarthy J, et al. Covid-19: ethical challenges for nurses. Hastings Cent Rep [Internet]. 2020 May 14; 50(3): 35-9. PMid:32410225 https://doi.org/10.1002/hast.1110

[3] Ramaci T, Barattucci M, Ledda C, et al. Social stigma during COVID19 and its impact on HCWs outcomes. Sustainability [Internet]. 2020 May 8; 12(9): 3834-47. https://doi.org/10.3390/su120938 34

[4] Brunworth J. Teaching nursing students in the COVID-unknown. Elsevier Connect [Internet]. 2020 May 6. Available from: https://www.elsevier.com/connect/teaching-nursing -students-in-the-covid-unknown

[5] Klar RT. Nurse educators as agents of change in the SARS-CoV-2 pandemic. Nurs Womens Health [Internet]. 2020 Aug; 24(4): 2535. PMid:32659222 https://doi.org/10.1016/j.nwh.2020.0 5.010
[6] Shen X, Zou X, Zhong X, et al. Psychological stress of ICU nurses in the time of COVID-19. Crit Care [Internet]. 2020 May 6; 24(1): 200. PMid:32375848 https://doi.org/10.1186/s13054-020 -02926-2

[7] Stockman F, Baker M. Nurses battling coronavirus beg for protective gear and better planning. New York Times [Internet]. $2020 \mathrm{Mar}$ 20. Available from: https://www.nytimes . com/2020/03/05/u s/coronavirus-nurses.html

[8] Wood, C. Nursing in a pandemic. Br J Nurse [Internet]. 2020 May 14; 29(9): 498. PMid:32407233 https://doi .org/10.12968/b jon.2020.29.9.498

[9] Merill S. Teaching through a pandemic: a mindset for this moment. Edutopia [Internet]. 2020 Mar 19. Available from: https://www.edutopia.org/article/teaching-thr ough-pandemic-mindset-moment

[10] Morin KH. Nursing education after COVID-19: same or different? [Editorial]. J Clin Nurs [Internet]. 2020 May 16; 29(17-18): 3117-9. PMid:32416017 https://doi.org/10.1111/jocn. 15322

[11] World Health Organization. Coronavirus disease (COVID19) Situation reports [Internet]. 2020. Available from: 
https://www. who.int/emergencies/diseases/novel -coronavirus-2019/situation-reports/

[12] Johns Hopkins University Medicine.[Internet]. Coronavirus resource center. 2020. Available from: https ://coronavirus.jhu.edu/ map.html

[13] Lingling ZD, Anchen Guan X, Zongfu DH, et al. Global COVID19: Warnings and suggestions based on experience of China. J Glob Hlth [Internet]. 2020; 10(1): 1-10. PMid:32509294 https: //doi.org/10.7189/jogh.10.011005

[14] Huang L, Xu FM, Liu HR. Emotional responses and coping strategies of nurses and nursing college students during Covid-19 outbreak [Preprint]. medRxiv. 2020 Aug 7; 15(8): e0237303. PMid:32764825 https://doi.org/10.1371/journal.pone.0237303

[15] Bettiza S. Italy's medical workers: we became heroes but they've already forgotten us. BBC World Service. 2020 May 26. Available from: https : //www.bbc. com/news/world-europe-52784120

[16] Savitsky B, Findling Y, Ereli A, et al. Anxiety and coping strategies among nursing students during the covid-19 pandemic. Nurs Educ Pract [Internet]. $2020 \mathrm{Jul}$; 46. PMid:32679465 https : //doi .org/ 10.1016/j.nepr. 2020.102809

[17] Frellick M. How the pandemic has affected doctors, nurses globally: Poll. Medscape Nurse [Internet]. 2020 Jun 11. Available from: https ://www.medscape.com/viewarticle/932171?nlid $=135907$ _4622\&src=WNL_mdplsnews_200612_mscpedit_nur s\&uac $=260241 \mathrm{MZ} \&$ spon=24\&impID $=2417216 \& \mathrm{faf}=1 \# \mathrm{vp} \_1$

[18] Newby JC, Mabry MC, Carlisle BA, et al. Reflections on nursing ingenuity during the COVID-19 pandemic. J Neurosci Nurs [Internet]. 2020 Oct; 52(5): E13-6. PMid:32221059 https : //doi .org/10.1 097/JNN . 0000000000000525

[19] Montauk T, Kuhl EA. COVID-related family separation and trauma in the intensive care unit. Psychol Trauma [Internet]. 2020 Aug; 12(S1): S96-7. PMid:32567872 https ://doi.org/10.1037/tr a0000839

[20] Fairhill J. Support for nurses during the pandemic. Br J Com Nurs [Internet]. 2020 Aug 2; 25(8): 369. PMid:32757892 https : //doi.org/10.12968/bjcn.2020.25.8.369

[21] Hofmeyer A, Taylor R, Kennedy K. Knowledge for nurses to better care for themselves so they can better care for others during the Covid-19 pandemic and beyond. Nurs Educ Today [Internet]. 2020 Nov; 94: 104503. PMid:32980179 https ://doi.org/10.1016/ j.nedt. 2020.104503

[22] Labrague L, McEnroe-Petitte D, Gloe D, et al. A literature review on stress and coping strategies in nursing students. J Ment Health [Internet]. 2016 Dec 14; 26(5): 471-80. PMid:27960598 https ://doi.org/10.1080/09638237.2016.1244721

[23] Pryjmachuk S, McWilliams C, Hannity B, et al. Transitioning to university as a nursing student: thematic analysis of written reflections. Nurs Educ Today [Internet]. 2019 Mar; 74: 54-60. PMid:30580181 https://doi.org/10.1016/j.nedt.2018.12.003

[24] Chen CJ, Chen YC, Sung HC, et al. The prevalence and related factors of depressive symptoms among junior college nursing students: a cross-sectional study. J Psychiatr Ment Health Nurs [Internet]. 2015 Jul 7; 22(8): 590-8. PMid:26149070 https ://doi .org/10.1111/ jpm. 12252

[25] Magnussen L, Amundson MJ. Undergraduate nursing student experience. Nurs Health Sci [Internet]. 2003 Nov 11; 5(4): 261-7. PMid:14622377 https : //doi.org/10.1046/j.1442-2018. 20 $03.00158 . x$
[26] Chernomas WM, Shapiro C. Stress, depression, and anxiety among under-graduate nursing students. Int J Nurs Educ Schol [Internet] 2013 November 7; 10(1): 255-6. PMid:24200536 https : //doi .or g/10.1515/ijnes-2012-0032

[27] Seyedrasooli A, Zamanzadeh V, Ghahramanian A, et al. Nursing educators' experiences regarding students' mistakes in clinical settings. Iran J Nurs Midwifery Res. 2019 November 7; 24(6): 462-8. PMid:31772922 https://doi.org/10.4103/ijnmr. IJNMR_46 $-19$

[28] Vogel S, Schwabe L. Learning and memory under stress: implications for the classroom. NPJ Sci Learn [Internet]. 2016 Jun 29; 1 : 6011. PMid:30792896 https://doi.org/10.1038/npjscilear n. 2016.11

[29] Lovric R, Farcic N, Miksic S, et al. Studying during the COVID-19 pandemic: a qualitative inductive content analysis of nursing students' perceptions and experiences. Educ Sci [Internet]. $2020 \mathrm{Jul} 21$; 10: 1-18. https://doi.org/10.3390/educsci10070188

[30] Shoes T. Learning during stressful times. Learn Mem [Internet]. 2004 Mar-Apr; 11(2): 137-44. PMid:15054128 https://doi.org/10 $.1101 / \mathrm{lm} .66604$

[31] Romero-Blanco C, Rodríguez-Almagro J, Onieva-Zafra MD, et al Sleep pattern changes in nursing students during the COVID-19 lockdown. Int J Environ Res Public Health [Internet]. 2020 Jul 20; 17: 1-11. PMid:32698343 https://doi.org/10.3390/ijerph1714 5222

[32] Siciliano McLaughlin MA, Saffold T, Johnson SA. Teaching nursing students during COVID-19. New Jersey Nurse \& Institute for Nursing Newsletter [Internet]. 2020 Jul; 50(3): 12. Available from: https://d3ms3kxrsap50t.cloudfront.net/uploads/ publication/pdf/2077/New_Jersey_Nurse_7_20.pdf

[33] Supiano B. Pandemic pedagogy and the limits of compassion. Chronicle of Higher Education. 2020 Jun 19. Available from: https://www.chronicle.com/article/Pandemic-Ped agogythe/249024?cid=wcontentlist

[34] Dewart G, Corcoran L, Thirsk L, et al. Nursing education in a pandemic: academic challenges in response to COVID-19. Nurse Educ Today [Internet]. 2020 Sep; 92. PMid:32502723 https ://doi .or g/10.1016/j.nedt. 2020.104471

[35] Sitzman K, Watson J. Chapter 2: overview of Watson's theory (10 caritas processes). In: Sitzman K, Watson J, editors. Caring science, mindful practice: implementing Watson's human caring theory. New York: Springer; 2014. p. 17-21.

[36] Watson J. Intentionality and caring-healing consciousness: A practice of transpersonal nursing. Holist Nurs Pract [Internet]. $2002 \mathrm{Jul}$; 16(4): 12-9. PMid:12060941 https://doi.org/10.1097/00004650-2 00207000-00005

[37] Darby F. 5 ways to connect with online students. Chronicle of Higher Education. 2020, Jun 26. Available from: https : //www . chronicl e.com/article/5-Ways-to-Connect-With-Online

[38] Ingraham KC, Davidson, SJ, Yonge O. Student-faculty relationships and its impact on academic outcomes. Nurse Educ Today [Internet]. 2018 Dec; 71: 17-21. PMid:30212706 https ://doi .org/10.101 6/j.nedt. 2018.08 .021

[39] Leigh J, Vasilica C, Dron R, et al. Redefining undergraduate nurse teaching during the coronavirus pandemic: use of digital technologies Br J Nurse [Internet]. 2020, May 28; 29(10): 566-9. PMid:32463742 https://doi.org/10.12968/bjon.2020.29.10.566 